\title{
Oxygenation of the cerebrospinal fluid with artificial cerebrospinal fluid can ameliorate a spinal cord ischemic injury in a rabbit model
}

\author{
Keisuke Kanda, MD, Osamu Adachi, MD, PhD, Satoshi Kawatsu, MD, PhD, Ko Sakatsume, MD,
} Kiichiro Kumagai, MD, PhD, Shunsuke Kawamoto, MD, PhD, and Yoshikatsu Saiki, MD, PhD

\section{ABSTRACT}

Objective: We evaluated the effect of cerebrospinal fluid oxygenation for the prevention of spinal cord ischemic injury after infrarenal aortic occlusion in a rabbit model.

Methods: Twenty white Japanese rabbits were categorized into the following 4 groups (5 in each): group $\mathrm{S}$ (sham), balloon catheter insertion on to the aorta; group $\mathrm{C}$ (control), spinal cord ischemic injury by infrarenal abdominal aortic balloon occlusion for 15 minutes; group $\mathrm{N}$ (nonoxygenated), spinal cord ischemic injury with cerebrospinal fluid replacement by nonoxygenated artificial cerebrospinal fluid; and group $\mathrm{O}$ (oxygenated), spinal cord ischemic injury with cerebrospinal fluid replacement by nanobubble-oxygenated artificial cerebrospinal fluid. The changes in cerebrospinal fluid partial pressure of oxygen during the periischemic period, modified Tarlov score, and histopathology of the spinal cord 48 hours after aortic maneuvers were evaluated.

Results: Cerebrospinal fluid partial pressure of oxygen significantly increased in group $\mathrm{O}$ compared with group $\mathrm{N}$ after cerebrospinal fluid replacement $(254.5 \pm 54.8 \mathrm{~mm} \mathrm{Hg}$ vs $136.1 \pm 43.5 \mathrm{~mm} \mathrm{Hg}, P=.02)$. After 15 minutes of spinal cord ischemic injury, cerebrospinal fluid partial pressure of oxygen in group $\mathrm{C}$ decreased to $65.8 \pm 18.6 \mathrm{~mm} \mathrm{Hg}$ compared with baseline $(148.8 \pm 20.6 \mathrm{~mm} \mathrm{Hg}$, $P<.01$ ), whereas cerebrospinal fluid partial pressure of oxygen in group $\mathrm{O}$ was maintained at remarkably high levels after spinal cord ischemic injury $(291.9 \pm 51.8 \mathrm{~mm} \mathrm{Hg})$, which was associated with improved neurologic function, with $20 \%$ of spinal cord ischemic injury having a Tarlov score less than 5 compared with $100 \%$ of spinal cord ischemic injury in group C. Preservation of anterior horn neurons in groups $\mathrm{N}$ and $\mathrm{O}$ was confirmed by histopathologic analysis with significant reduction of degenerated neurons compared with group C.

Conclusions: Cerebrospinal fluid oxygenation with artificial cerebrospinal fluid can exert a protective effect against spinal cord ischemic injury in rabbits. ( $\mathrm{J}$ Thorac Cardiovasc Surg 2016;152:1401-9)

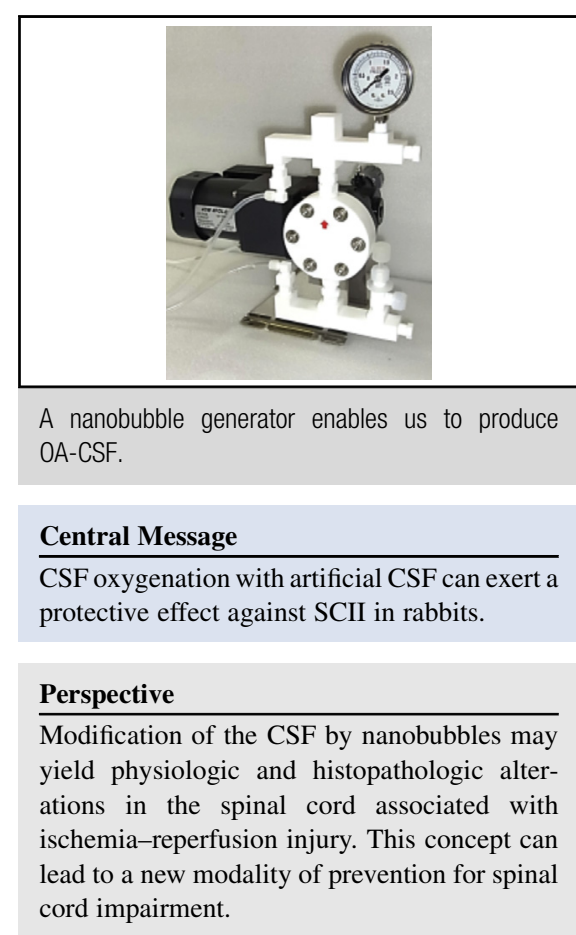

See Editorial Commentary page 1410.

\footnotetext{
From the Division of Cardiovascular Surgery, Tohoku University Graduate School of Medicine, Sendai, Japan.

This study is funded by Grants-in-Aid for Scientific Research (KAKENHI). Research Project Number: 26670615.

Read at the 96th Annual Meeting of The American Association for Thoracic Surgery, Baltimore, Maryland, May 14-18, 2016.

Received for publication Sept 23, 2015; revisions received March 28, 2016; accepted for publication April 5, 2016; available ahead of print Sept 15, 2016.

Address for reprints: Yoshikatsu Saiki, MD, PhD, Division of Cardiovascular Surgery, Tohoku University Graduate School of Medicine, 1-1 Seiryocho, Aoba-ku, Sendai 980-8574, Japan (E-mail: yoshisaiki@med.tohoku.ac.jp). $0022-5223 / \$ 36.00$

Copyright (c) 2016 by The American Association for Thoracic Surgery http://dx.doi.org/10.1016/j.jtcvs.2016.04.095
}

Spinal cord ischemic injury (SCII) after thoracoabdominal aortic aneurysm (TAAA) repair is a devastating complication for patients and a dreadful complication for cardiovascular surgeons. However, preventive methods against SCII

Scanning this QR code will take you to the article title page. To view the AATS 2015 Webcast, see the URL at the end of the article.

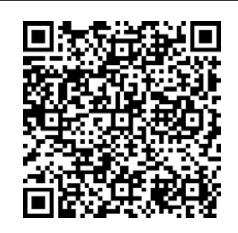




\section{Abbreviations and Acronyms \\ $\mathrm{CSF}=$ cerebrospinal fluid \\ OA-CSF $=$ oxygenated artificial cerebrospinal fluid \\ $\mathrm{Po}_{2} \quad=$ partial pressure of oxygen \\ SCII = spinal cord ischemic injury \\ TAAA $=$ thoracoabdominal aortic aneurysm}

have never been completely established. Many investigators have reported that its incidence rate ranges from $3.8 \%$ to $13.2 \% .{ }^{1-3}$ Paraplegia after TAAA repair severely affects patients' quality of life and activities of daily living.

SCII has been considered to be induced primarily by spinal cord ischemia during aortic crossclamping and subsequent reperfusion injury and perioperative hypotension with resultant decreased blood flow to the spinal cord via collateral circulations. ${ }^{4}$ Several maneuvers for spinal cord protection have been documented to date, including maintenance of mean aortic blood pressure during and after reparative surgery, ${ }^{5}$ use of hypothermia, ${ }^{6}$ local hypothermia around the spinal cord with epidural perfusion cooling, ${ }^{7}$ drainage of the cerebrospinal fluid (CSF), ${ }^{8,9}$ reattachment of the intercostal and lumbar arteries, ${ }^{10-12}$ and preconditioning of the paraspinal collateral network by segmental artery coil embolization. ${ }^{13}$ Furthermore, several drugs are reportedly promising candidates to prevent SCII in animals. ${ }^{14,15}$

We were intrigued with the report by Lips and colleagues ${ }^{16}$ on a phenomenon that occurs in the spinal cord tissue and the CSF during spinal cord ischemia. They clamped the lumbar and intercostal arteries in series from bottom to top in their pig model. They found that transcranial motor-evoked potentials diminished as CSF partial pressure of oxygen $\left(\mathrm{PO}_{2}\right)$ decreased after the critical segmental arteries connected to the Adamkiewicz artery were clamped. Thus, we formulated our hypothesis that the spinal cord tissue exposed to ischemia may consume $\mathrm{O}_{2}$ from the CSF, and cellular respiration in the spinal cord may be preserved, at least to some extent, with $\mathrm{O}_{2}$ transport via $\mathrm{PO}_{2}$ gradient. If we could supply some CSF supplemented with $\mathrm{O}_{2}$ externally, we might mitigate hypoxic SCII caused by ischemia. The purpose of this study was to examine the protective effect of CSF oxygenation against SCII during infrarenal aortic occlusion in a rabbit model.

\section{MATERIALS AND METHODS}

For the first step of this experiment, oxygenated artificial CSF (OA-CSF) was produced using a nanobubble generating device. We selected MA3FS (ASUPU, Shizuoka, Japan) as the nanobubble generating device (Figure 1, A) and ARTCEREB (Otsuka, Tokushima, Japan) as the irrigation and perfusion solution for cerebrospinal surgery. This solution mimics the electrolyte and other composition of CSF containing glucose, sodium chloride, calcium chloride hydrate, magnesium chloride, sodium bicarbonate, sodium chloride, potassium chloride, and monobasic potassium phosphate. A suction pipe and an exhaust pipe of the nanobubble generating device were put into $100 \mathrm{~mL}$ of ARTSEREB, and thus $\mathrm{O}_{2}$ nanobubbles were generated in the ARTSEREB for 15 minutes while drawing pure $\mathrm{O}_{2}$ at a speed of $1 \mathrm{~L} / \mathrm{min}$. After generating nanobubbles, we left it to rest for 2 minutes. After confirming the disappearance of bubbles visually, we measured $\mathrm{PO}_{2}$ in the ARTSELEB. Subsequently, we defined this fluid as OA-CSF.

\section{Animal Model, Surgical Procedure, and Cerebrospinal Fluid Oxygenating Protocol}

A total of 20 white male Japanese rabbits with body weights between $2.65 \mathrm{~kg}$ and $3.10 \mathrm{~kg}$ were included in this study. We divided them into 4 groups. Each group was defined as follows: group sham (group S), a micro-catheter was inserted into the intrathecal space and a balloon catheter was inflated in the infrarenal abdominal aorta for 5 seconds; group control (group C), a micro-catheter was inserted into the intrathecal space and the infrarenal abdominal aorta was occluded using a balloon catheter for 15 minutes; group nonoxygenated (group N), a micro-catheter was inserted into the intrathecal space and non-OA-CSF was injected into the intrathecal space via a micro-catheter at a rate of $10 \mathrm{~mL} / \mathrm{h}$ for 1 hour, and subsequently, their infrarenal abdominal aorta was occluded using a balloon catheter for 15 minutes while continuing to inject non-OA-CSF; group oxygenated (group $\mathrm{O}$ ), a micro-catheter was inserted into the intrathecal space and OA-CSF was injected via a micro-catheter at a rate of $10 \mathrm{~mL} /$ $\mathrm{h}$ for 1 hour, after which their infrarenal abdominal aorta was occluded using a balloon catheter for 15 minutes while continuing to inject OA-CSF.

All rabbits were initially anesthetized with $5.0 \%$ isoflurane added to mixed gas regulated to a fraction of inspired oxygen 0.5 , and $50 \mathrm{mg} / \mathrm{kg}$ of ketamine hydrochloride was administered intramuscularly. Maintenance of the anesthesia was performed by inhalation of $2.0 \%$ to $3.0 \%$ isoflurane and mixed gas controlled to a fraction of inspired oxygen of 0.5 . The rabbits were repeatedly administered $50 \mathrm{mg} / \mathrm{kg}$ of ketamine hydrochloride intramuscularly, if necessary. Animals breathed spontaneously with facemasks, and they did not undergo endotracheal intubation or mechanical ventilation. Ringer's lactate solution (Lactec, Otsuka, Tokushima, Japan) was infused as maintenance fluid at $7 \mathrm{~mL} / \mathrm{kg} / \mathrm{h}$ of infusion rate during the procedures. First, the rabbits were placed in the prone position, and a skin incision was made at the level of L1 and L2. We carefully punctured the intrathecal space with an 18-gauge cannula and inserted a polyurethane catheter (UNIEVER, UNYSIS, Koshigaya, Japan) with a diameter of $0.9 \mathrm{~mm}$ in the intrathecal space after recognizing that the CSF flowed backward via the cannula. The tip of the catheter was set $2 \mathrm{~cm}$ beyond the point of the cannula. Subsequently, the CSF was sampled and the artificial CSF was injected using this catheter. Thereafter, the rabbits were placed in the supine position. The right femoral artery was exposed and taped. Heparin sodium $(100 \mathrm{U} / \mathrm{kg})$ was administered as an intravenous bolus for approximately 10 minutes before occluding the infrarenal abdominal aorta. One hour after the placement of the intrathecal catheter and injection of the artificial CSF, the right femoral artery was incised, and a 3F Fogarty balloon catheter (LeMaitre Vascular, Inc, Burlington, Mass) was inserted up to the infrarenal abdominal aorta. The Fogarty balloon catheter was advanced by $15 \mathrm{~cm}$ from the inguinal ligament and inflated for 5 seconds in group $\mathrm{S}$ and for 15 minutes in groups $\mathrm{C}, \mathrm{N}$, and $\mathrm{O}$. Many authors have reported that the occlusion of the infrarenal abdominal aorta for 15 minutes led to paraparesis in rabbits, ${ }^{17,18}$ and we decided to adopt this rabbit model for the purpose of evaluating the protective effects of our CSF modulations. Regarding assurance of the precise position of an endoluminal balloon, we have conducted a pilot study using 2 rabbits to examine it. We could reproducibly confirm via laparotomy that an expanded balloon was positioned at 1 to $2 \mathrm{~cm}$ distal to the renal artery after defining the uniform insertion depth as reported in the literature previously. ${ }^{17,18}$ After the completion of the procedures, all catheters were immediately removed and the wounds were closed. All rabbits that were confirmed with awareness from anesthesia were taken back to the cages. Fortyeight hours after the elapse of the spinal cord ischemia, all rabbits were neurologically evaluated for hind limb function by the modified Tarlov 

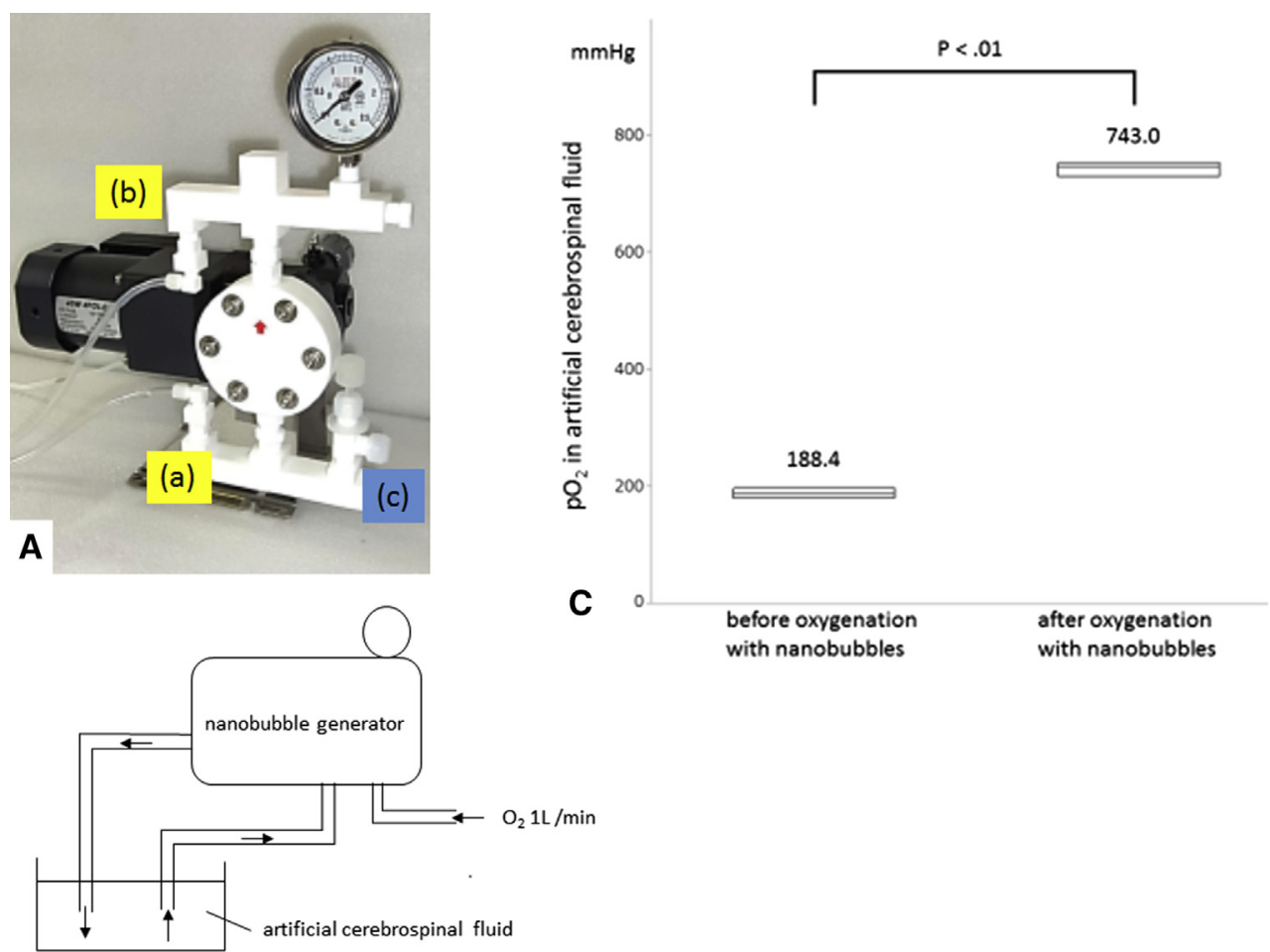

with nanobubbles with nanobubbles

B

FIGURE 1. A, MA3FS (nanobubble generator) (ASUPU, Shizuoka, Japan). B, Schema of nanobubble generation setup. Artificial CSF is drained into MA3FS via an inlet (a). MA3FS pressurizes pure oxygen via an air hole (c) into the circulating artificial CSF and pumps out OA-CSF from an outlet (b). $\mathrm{C}, \mathrm{PO}_{2}$ of artificial CSF before and after nanobubble generation. Mann-Whitney $U$ test. $\mathrm{Po}_{2}$, Partial pressure of oxygen.

score, ${ }^{19}$ and all rabbits were then euthanized with acute administration of efficient potassium chloride under deep anesthesia. Vertebral arches of T12 and L6 were immediately incised, and the spinal cords between T12 and L6 were removed as pathology specimens. The spinal cords that were obviously injured by insertion of intrathecal catheter were excluded from this examination, and 7 animals in total were excluded for this reason. There was no mortality encountered during this experiment. Also, mean blood pressure during the 15 minutes of spinal cord ischemia, rectal temperature, $\mathrm{PO}_{2}$ of arterial blood, concentration of hemoglobin, and CSF pressure, which were reportedly the other factors to influence the course of neurologic function, were monitored. All animals were raised with free access to water and food before and after this experiment, and not administered with any other drugs. This study was implemented in accordance with Regulation for Animal Experiments and Related Activities at Tohoku University and approved by the Animal ethical committee at the Tohoku University (2013).

\section{Measurement of Cerebrospinal Fluid Partial Pressure of Oxygen}

Measurement of CSF- $\mathrm{PO}_{2}$ was performed at the following time points in each group. In group $\mathrm{S}, \mathrm{CSF}-\mathrm{PO}_{2}$ was measured at the time when the intrathecal catheter was inserted. In group C, CSF- $\mathrm{PO}_{2}$ was measured at the point of insertion of intrathecal catheter and at a point 15 minutes after spinal cord ischemia. In groups $\mathrm{N}$ and $\mathrm{O}, \mathrm{CSF}-\mathrm{Po}_{2}$ was measured at the point of insertion of intrathecal catheter, at the cessation of continuous injection of artificial CSF, and at a point 15 minutes after spinal cord ischemia. Also, $\mathrm{PO}_{2}$ of nonoxygenated and $\mathrm{OA}-\mathrm{CSF}$ was measured just before commencing the injection into the intrathecal space. We selected epoc systems (Alere Inc, Waltham, Mass) to measure CSF- $\mathrm{Po}_{2}$ and $\mathrm{Po}_{2}$ of the artificial CSF because epoc systems enabled us to measure $\mathrm{Po}_{2}$ with just $0.1 \mathrm{~mL}$ of samples. However, the maximum $\mathrm{Po}_{2}$ measured with epoc systems is limited to $750 \mathrm{~mm} \mathrm{Hg}$.

\section{Neurologic Evaluation}

Neurologic function of the hind limbs was assessed 48 hours after spinal cord ischemia using the modified Tarlov score ${ }^{20}$ as follows: $0=$ no movement, $1=$ slight movement, $2=$ sits with assistance, $3=$ sits alone, $4=$ weak hop, and $5=$ normal hop.

\section{Histopathologic Evaluation}

The removed spinal cord was immediately dipped into $10 \%$ formalin neutral buffer solution (Wako Pure Chemical Industries, Ltd, Osaka, Japan) and fixed for more than 1 week. Subsequently, paraffin-embedded samples were made and cross-sections of the spinal cord were stained with hematoxylin-eosin.

Histopathologic examination was performed by a pathologist who was blinded to the study groups. The gray matter at the L2 and L3 vertebrae was divided into 4 sections in vertical and horizontal directions with the central canal as center. Of these sections, 1 section from the anterior horn was selected, and the anterior horn neurons were counted. Only neurons with a cell body having a minor diameter 4 times as large as a nucleus of an astrocyte were regarded as anterior horn neurons for the purpose of excluding the neurons with pyknotic changes and small cross-sections. We defined normal anterior horn neurons as having a polygonal body with round and basophilic nuclei and degenerated anterior horn neurons as being eosinophilic, without nuclei, or chromatolytic neurons. Dark neurons were regarded as normal because this was generally considered as an artifact that occurred during fixation of the nerve tissues. 
TABLE 1. Intraoperative data

\begin{tabular}{|c|c|c|c|c|c|}
\hline Variable & Group $\mathbf{S}$ & Group C & Group N & Group O & $P$ value \\
\hline Samples & 5 & 5 & 5 & 5 & \\
\hline Body weight (kg) & $3.0 \pm 0.1$ & $2.9 \pm 0.1$ & $3.0 \pm 0.1$ & $2.8 \pm 0.2$ & .49 \\
\hline CSF pressure at baseline $(\mathrm{mm} \mathrm{Hg})$ & $8.6 \pm 1.9$ & $9.4 \pm 0.9$ & $12.2 \pm 4.8$ & $9.5 \pm 3.1$ & .14 \\
\hline Mean blood pressure $(\mathrm{mm} \mathrm{Hg})$ & $98.2 \pm 12.6$ & $104.0 \pm 13.4$ & $95.2 \pm 8.3$ & $94.5 \pm 5.5$ & .55 \\
\hline Mean rectal temperature $\left({ }^{\circ} \mathrm{C}\right)$ & $37.6 \pm 1.0$ & $37.8 \pm 1.0$ & $37.5 \pm 0.7$ & $37.4 \pm 0.4$ & .63 \\
\hline Mean arterial blood $-\mathrm{Po}_{2}(\mathrm{~mm} \mathrm{Hg})$ & $258.3 \pm 29.3$ & $299.7 \pm 19.4$ & $356.3 \pm 123.0$ & $352.2 \pm 129.3$ & .16 \\
\hline Mean hemoglobin concentration $(\mathrm{g} / \mathrm{dL})$ & $11.7 \pm 0.6$ & $11.8 \pm 0.6$ & $11.0 \pm 1.4$ & $11.4 \pm 0.3$ & .59 \\
\hline
\end{tabular}

$\mathrm{CSF}$, Cerebrospinal fluid; $\mathrm{PO}_{2}$, partial pressure of oxygen. Kruskal-Wallis test.

Histopathologic evaluation was done with the values of normal anterior horn neurons.

\section{Statistical Analysis}

All data were expressed as the mean \pm standard deviation. Variance of continuous variables in intraoperative data was analyzed with the KruskalWallis test. Values of measured $\mathrm{Po}_{2}$ and anterior horn cell were compared between each group with the Mann-Whitney $U$ test (2-sided). Incidence rates of paraparesis were analyzed with the Fisher exact test (1-sided), and extents of the modified Tarlov scores were analyzed with the MannWhitney $U$ test. Statistical analysis was performed with JMP Pro 11.0.0 software (SAS Institute, Inc, Cary, NC).

\section{RESULTS}

\section{Production of Oxygenated Artificial Cerebrospinal Fluid}

Mean baseline $\mathrm{PO}_{2}$ of artificial CSF, which was nonoxygenated, was $188.4 \pm 8.1 \mathrm{~mm} \mathrm{Hg}$. Mean $\mathrm{Po}_{2}$ of OA-CSF was $743.0 \pm 11.6 \mathrm{~mm} \mathrm{Hg}$ and was significantly higher than that of non-OA-CSF $(P<.01)$ (Figure $1, C$ ).

\section{Profiles and Intraoperative Characteristics of Animals}

The baseline characteristics were approximately equal among all 4 groups (Table 1).

\section{Measurement of Partial Pressure of Oxygen in Cerebrospinal Fluid and Artificial Cerebrospinal Fluid}

Mean values of CSF- $\mathrm{Po}_{2}$ were $113.5 \pm 5.1 \mathrm{~mm} \mathrm{Hg}$, $148.8 \pm 20.6 \mathrm{~mm} \mathrm{Hg}, 130.8 \pm 16.8 \mathrm{~mm} \mathrm{Hg}$, and $140.5 \pm 46.5 \mathrm{~mm} \mathrm{Hg}$ in groups $\mathrm{S}, \mathrm{C}, \mathrm{N}$, and $\mathrm{O}$, respectively, during insertion of the intrathecal catheter $(P=.13)$. In group $\mathrm{N}$, the mean value of non-OA-CSF, which was continuously injected into the intrathecal space for 1 hour, was $198.1 \pm 6.1 \mathrm{~mm} \mathrm{Hg}$. In group O, 1 sample of OACSF was $730.5 \mathrm{~mm} \mathrm{Hg}$ and 4 samples of OA-CSF were greater than $750 \mathrm{~mm} \mathrm{Hg}$. After 1 hour of intrathecal injection, mean values of $\mathrm{CSF}-\mathrm{Po}_{2}$ just before spinal cord ischemia were $136.1 \pm 43.5 \mathrm{~mm} \mathrm{Hg}$ and $254.5 \pm 54.8 \mathrm{~mm} \mathrm{Hg}$ in groups $\mathrm{N}$ and $\mathrm{O}$, respectively $(P=.02)$ (Figure 2, $A$ ). Mean values of $C S F-\mathrm{Po}_{2}$ after spinal cord ischemia for 15 minutes were $65.8 \pm 18.6 \mathrm{~mm} \mathrm{Hg}$, $99.2 \pm 16.3 \mathrm{~mm} \mathrm{Hg}$, and $291.9 \pm 51.8 \mathrm{~mm} \mathrm{Hg}$ in groups $\mathrm{C}, \mathrm{N}$, and $\mathrm{O}$, respectively (Figure $2, A$ ). In group $\mathrm{C}$, mean value of $\mathrm{CSF}-\mathrm{PO}_{2}$ was significantly lower after 15 minutes of spinal cord ischemia than before 15 minutes of spinal cord ischemia $(P<.01)$, but there were no significant differences between the mean values of CSF- $\mathrm{Po}_{2}$ before and after 15 minutes of spinal cord ischemia in group $\mathrm{N}(P=.09)$.
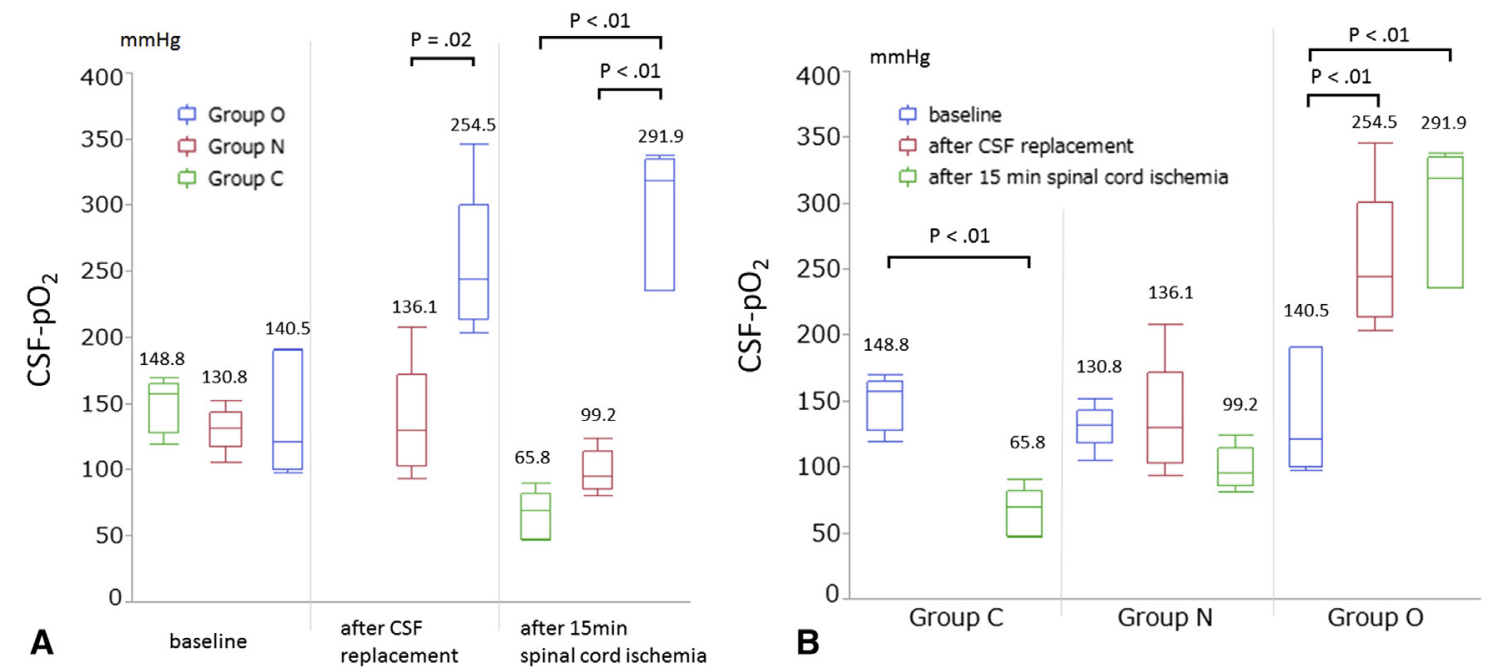

FIGURE 2. A, Differences in $\mathrm{CSF}-\mathrm{Po}_{2}$ at baseline, after CSF replacement, and after 15 minutes spinal cord ischemia. Intergroup comparisons. B, Changes of CSF- $\mathrm{Po}_{2}$ in groups $\mathrm{C}, \mathrm{N}$, and $\mathrm{O}$. Intergroup comparisons. Mann-Whitney $U$ test. $\mathrm{CSF}$, Cerebrospinal fluid; $\mathrm{Po}_{2}$, partial pressure of oxygen. 


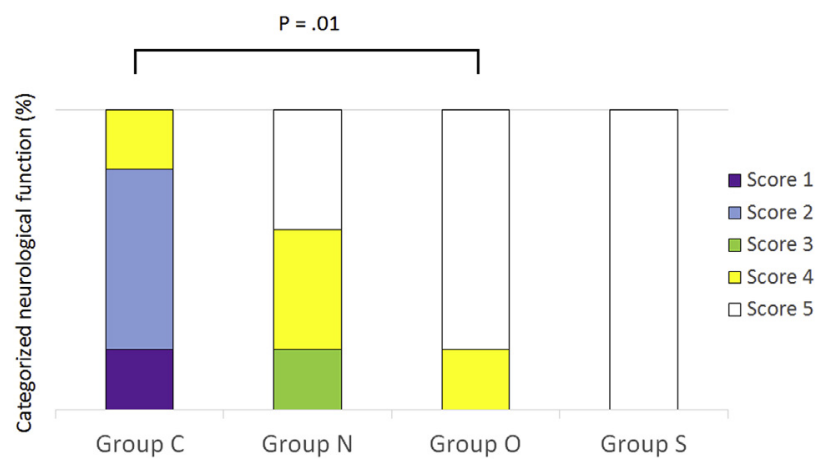

FIGURE 3. Frequency and extent of modified Tarlov score in groups $C$, $\mathrm{N}, \mathrm{O}$, and $\mathrm{S}$. The smaller score represents the severer neurologic impairment. Score 5 reflects intact neurologic function. $P$ value is derived from statistical analysis with Mann-Whitney $U$ test on extents of the modified Tarlov score.

Conversely, in group O, mean value of CSF- $\mathrm{Po}_{2}$ after $15 \mathrm{mi}-$ nutes spinal cord ischemia was significantly higher than that of the baseline $(P<.01)$, and we attained success in producing oxygenated environment around the spinal cord. (Figure 2, B).

\section{Neurologic Evaluation}

Neurologic evaluation was performed 48 hours after spinal cord ischemia using the modified Tarlov score. Incidence rates of paraparesis were $100 \%, 60 \%, 20 \%$, and $0 \%$ in groups $\mathrm{C}, \mathrm{N}, \mathrm{O}$, and $\mathrm{S}$, respectively, but there were no significant differences in the incidence rate of paraparesis between each group. Extents of the modified Tarlov score in group $\mathrm{O}$ were significantly higher than those of group $\mathrm{C}(P=.01 ; P=$ not significant, between other 2 groups) (Figure 3 ).

\section{Histopathologic Evaluation}

The mean values of the anterior horn neurons per section at the L2 vertebra were $8.0 \pm 1.2,8.4 \pm 1.5$, and $9.8 \pm 2.0$, and at the L3 vertebra were $8.6 \pm 1.9,5.8 \pm 1.9$, and $7.6 \pm 2.4$ in groups $\mathrm{C}, \mathrm{N}$, and $\mathrm{O}$, respectively, and there were no significant differences between the groups (L2: $P=.25$, L3: $P=.20)$. However, the mean values of normal neurons at the $\mathrm{L} 2$ vertebra were $1.4 \pm 1.5,6.0 \pm 2.7$, and $7.0 \pm 2.1$, and at the L3 vertebra were $1.0 \pm 1.2$, $4.8 \pm 1.7$, and $5.8 \pm 2.5$ in groups $\mathrm{C}, \mathrm{N}, \mathrm{O}$, respectively. Compared with the other groups, the normal anterior horn neurons in group $\mathrm{C}$ were significantly less than in the other groups at both L2 and L3 vertebrae (L2; $P=.020$ [vs group $\mathrm{N}$ ], $P=.014$ [vs group O] L3; $P=.025$ [vs group $\mathrm{N}$ ], $P=.011$ [vs group O]) (Figure 4, $A$ and $B$ ) Representative histopathologic images of the anterior horn of the spinal cord in groups $\mathrm{S}, \mathrm{C}, \mathrm{N}$, and $\mathrm{O}$ are shown in Figure 5, A, $B, C$, and $D$, respectively.

\section{DISCUSSION}

We have proposed a new concept to modify CSF with nanobubble technology and demonstrated that this CSF oxygenation ameliorated SCII for the first time. We believe that the application of nanobubble may evoke a new strategy for spinal cord protection against ischemic-reperfusion injury.
L2 level

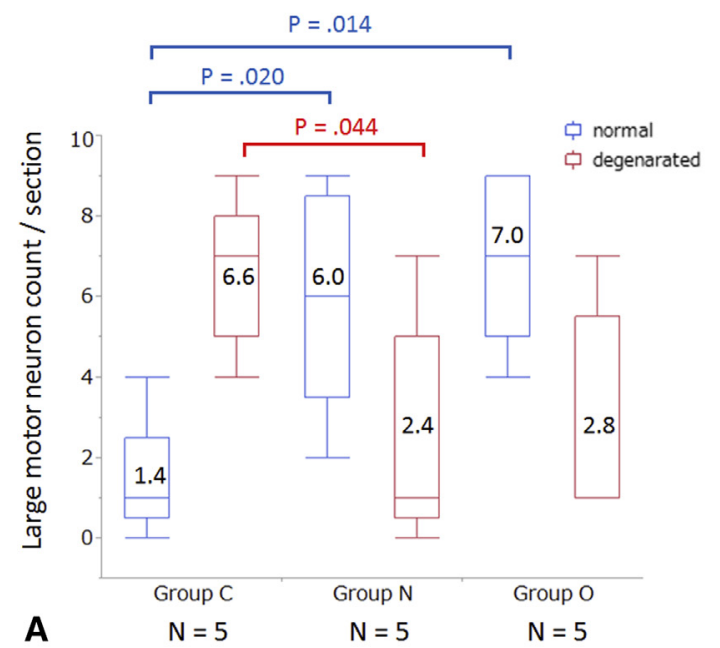

L3 level

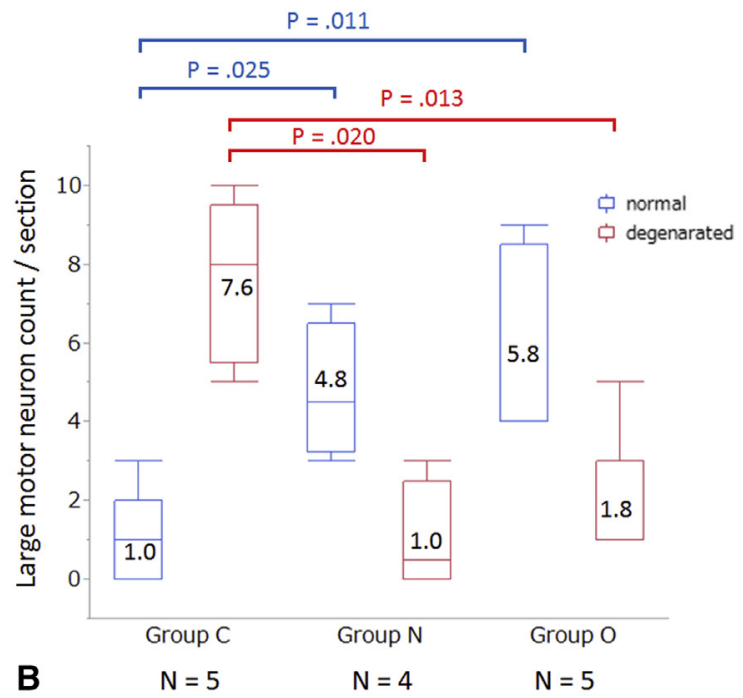

FIGURE 4. Assessment of motor neurons. A, At the spinal cord level of $\mathrm{L} 2$, normal anterior horn neurons were dominant in groups $\mathrm{N}$ and $\mathrm{O}$ compared with group C. B, At the spinal cord level of L3, degenerated neurons were less in groups $\mathrm{N}$ and O compared with group C, similar to the L2 level spinal cord. Mann-Whitney $U$ test. 

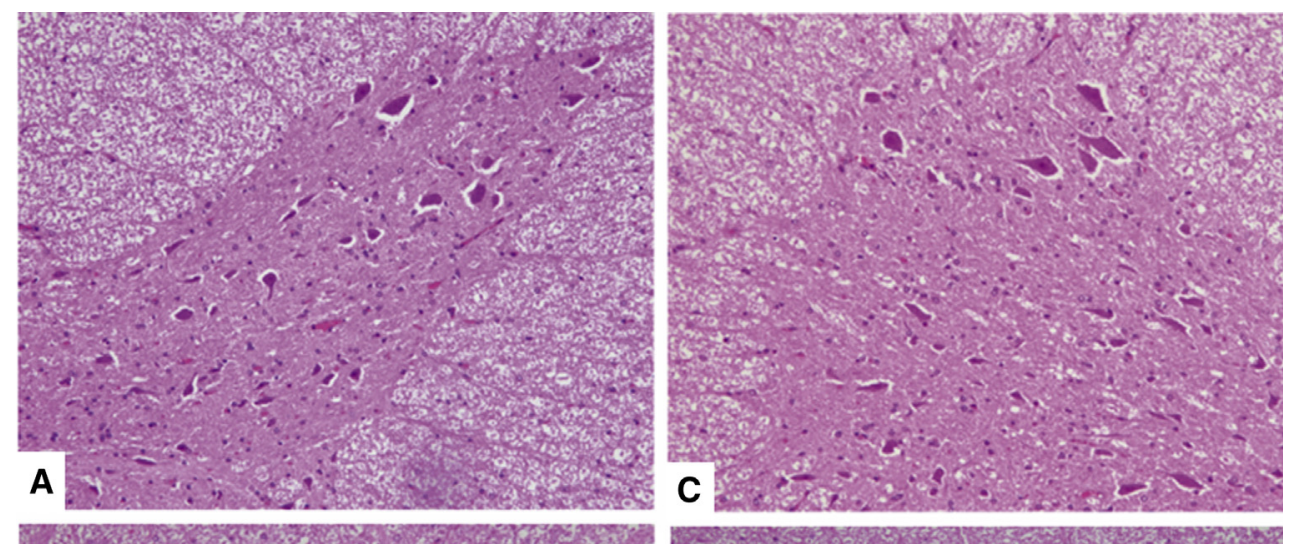

A
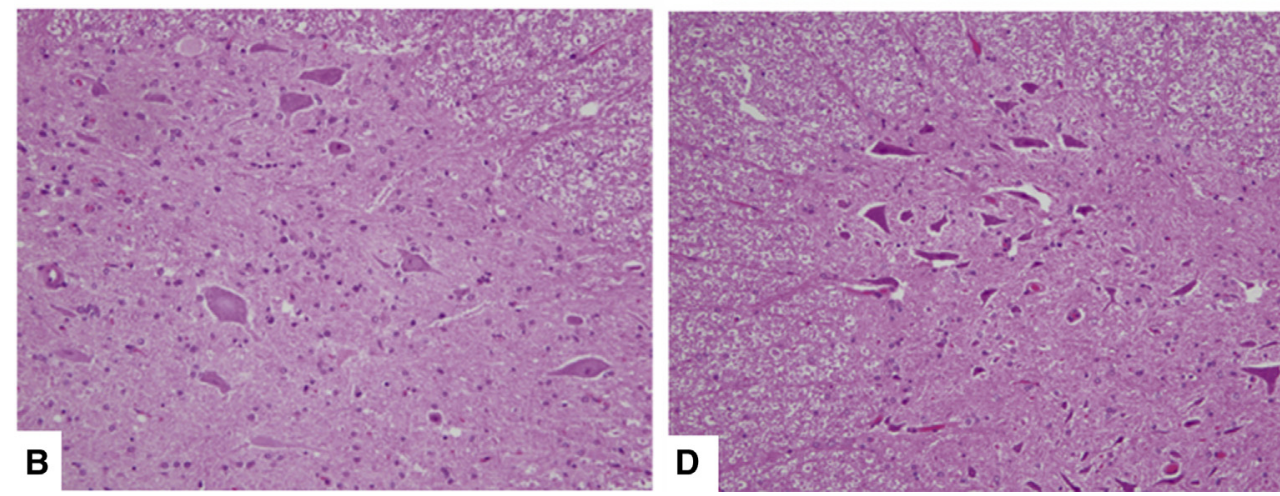

FIGURE 5. Representative histopathologic images of the spinal cord of groups $\mathrm{S}, \mathrm{C}, \mathrm{N}$, and $\mathrm{O}$ (hematoxylin-eosin stain; magnification $\times 200$ ). A, In group $\mathrm{S}$, no ischemic injury was detected. B, In group C, more than $70 \%$ of motor neurons were found to be degenerated with eosinophilic or chromatolytic change. $\mathrm{C}$ and D, In groups $\mathrm{N}$ and $\mathrm{O}$, more than $80 \%$ of normal neurons with basophilic nuclei were preserved, and less degenerated neurons were evidently observed.

Lips and colleagues ${ }^{16}$ have reported that spinal cord ischemia was related to a decrease in CSF- $\mathrm{PO}_{2}$ and reduction of transcranial motor-evoked potentials in a pig model. Also, Hellberg and colleagues ${ }^{20}$ reported that monitoring of intrathecal $\mathrm{PO}_{2}$ after clamping the descending aorta can predict ultrastructural changes in the spinal cord in a pig model. Evidently, there seems to be a correlation between spinal cord ischemia and a decrease in $\mathrm{CSF}-\mathrm{PO}_{2}$. However, no one has investigated the reasons and mechanisms behind this phenomenon. We formulated the hypothesis that dissolved $\mathrm{O}_{2}$ in CSF diffuses into the spinal cord tissue according to the concentration gradient when $\mathrm{O}_{2}$ concentration in the spinal cord tissue decreases as the result of ischemia. Furthermore, we postulated that spinal cord tissue would not critically be short of $\mathrm{O}_{2}$ during ischemia if we could provide $\mathrm{O}_{2}$ in CSF. Creation of such particular circumstance around the spinal cord may develop into a novel strategy to protect the spinal cord against ischemic injury. A similar attempt for animal or human subjects has never been documented.

The unique characteristics of minute bubbles are gathering attention in engineering and agricultural fields. Zhukhovitskii $^{21}$ reported that nanobubbles had various physical characteristics. However, there are few reports on its use in the medical field. One of the outstanding characteristics of minute bubbles, called "microbubbles/ nanobubbles," is the production of fluid with a high degree of gas solubility. Matsuki and colleagues ${ }^{22}$ produced normal saline solution with a high degree of $\mathrm{O}_{2}$ solubility, which reached $985.6 \pm 27.1 \mathrm{~mm} \mathrm{Hg}$, and proved that the hyper-oxygenated solution contributed to significant oxygenation of the venous blood in pigs. We anticipate that this technology will be widely applied to other medical domains.

The rabbit model of paralysis induced by spinal cord ischemia with occlusion of the infrarenal abdominal aorta has been published many times and is regarded as an established procedure. Generally, many authors reported that rabbits manifested paraparesis if they were subjected to spinal cord ischemia for 15 minutes $^{18,23}$ and developed paraplegia if ischemic for 20 minutes ${ }^{15,24}$ under untreated conditions. In our present experiment, all rabbits in group $\mathrm{C}$, subjected to 15 minutes of spinal cord ischemia, developed paraparesis. On the other hand, only 1 rabbit in the oxygenated group manifested trivial paraparesis and 4 rabbits retained normal neurologic function of the hind limbs. Of note, the extents of SCII in group $\mathrm{O}$ were significantly lower than in group $\mathrm{C}$. Therefore, augmenting $\mathrm{CSF}-\mathrm{PO}_{2}$ might have the potential to protect against SCII. However, there were no significant 
differences between group $\mathrm{N}$ (pretreated with artificial CSF without nanobubble) and group $\mathrm{O}$ in terms of neurologic outcomes. We speculate that higher $\mathrm{Po}_{2}$ in non-OA-CSF compared with that in host CSF was due to some degree of protective effect on the ischemic spinal cord. Higher $\mathrm{PO}_{2}$ in non-OA-CSF was induced by oxygen in the atmosphere. Henry's law indicates that oxygen should dissolve in any fluid and $\mathrm{PO}_{2}$ should be at approximately $160 \mathrm{~mm} \mathrm{Hg}$ when atmospheric pressure in the standard condition is $760 \mathrm{~mm} \mathrm{Hg}$. Slightly even higher $\mathrm{PO}_{2}$ in the non-OA-CSF was affected by slightly higher pressure in the solution bag. Consequently, the postischemic value of $\mathrm{PO}_{2}$ in group $\mathrm{N}$ was $99.2 \mathrm{~mm} \mathrm{Hg}$, which is still as high as the normal value, whereas the postischemic value in group $\mathrm{C}$ was $65.8 \mathrm{~mm} \mathrm{Hg}$. These findings imply that nonoxygenated CSF can still be capable of providing a certain amount of oxygen to the spinal canal. Nonetheless, neurologic function in group $\mathrm{N}$ did not improve with statistical significance compared with group $\mathrm{C}$, whereas that in group $\mathrm{O}$ improved significantly. Accordingly, we infer from this rabbit experiment that hyperoxygenation of CSF with nanobubbles did not exert a superior protective effect against ischemic spinal cord injury compared with "mild oxygenation."

In this study, we decided to inject OA-CSF into the intrathecal space at the rate of $10 \mathrm{~mL} / \mathrm{h} 1$ hour before starting spinal cord ischemia; however, we have not optimized the conditions when the continuous injection should be commenced and with what speed the continuous injection should be delivered. Furthermore, although we could demonstrate the protective effect against 15 minutes of spinal cord ischemia, we have not examined how long the spinal cord could tolerate ischemia under the circumstance of oxygenated CSF.

Spinal drainage is one of the most widely used procedures during TAAA repair, and the safety of the procedure including an insertion of a catheter into intrathecal space has been established in the clinical area. ${ }^{8,9}$ However, we need to cautiously evaluate the safety and risk of continuous injection of OA-CSF. In fact, CSF pressure, which should be decreased using spinal drainage during the operation of TAAA repair, was increased in groups $\mathrm{N}$ and $\mathrm{O}$ in this experiment from $10 \mathrm{~mm} \mathrm{Hg}$ of mean prereplacement value to $20 \mathrm{~mm} \mathrm{Hg}$ of mean postreplacement value (detailed data are not shown). Thus, this method supposedly raises the concern of a potential adverse effect, although no obvious adverse effect was observed in this rabbit model. We may have to consider an adjuvant method to decrease CSF pressure, that is, an insertion of another intrathecal catheter for spinal drainage or use of a double-lumen catheter for injection and drainage. We clearly need to pursue a method to balance the maximal protective effect of CSF with nanobubbles on spinal cord protection against ischemia and its potential risk.
Finally, the method described in this article can be a new modality of protective strategy that is different from any other methods for spinal cord protection that have been reported. We expect that this method would enhance spinal cord protection when combined with other clinical available methods (eg, hypothermia), including general or regional cooling, and pharmacologic interventions, such as oral intake of memantine ${ }^{14}$ intravenous administration of edaravone, ${ }^{25}$ or intrathecal injection of papaverine. ${ }^{26}$ Our method does not theoretically interfere with these adjuvant protections, and it may confer synergistic effects if combined. Our present study with an animal model warrants further animal experiments.

\section{CONCLUSIONS}

CSF oxygenation with artificial CSF can exert a protective effect against SCII in rabbits. Modifications of CSF using nanobubble technology may deserve to be considered as a novel strategy for spinal cord protection.

\section{Webcast}

You can watch a Webcast of this AATS meeting presentation by going to: http://webcast.aats.org/2016/Video/ Tuesday/05-17-16_Ballroom_IV_0700_Kanda-800.mp4.

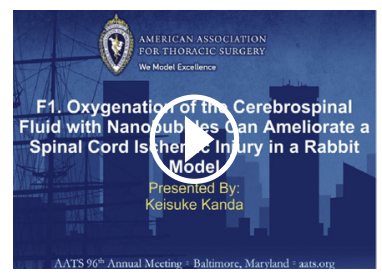

\section{Conflict of Interest Statement}

Authors have nothing to disclose with regard to commercial support.

The authors thank Dr Yuriko Saiki (Department of Molecular Pathology, Tohoku University Graduate School of Medicine) for her kind support with the histopathologic evaluation.

\section{References}

1. Coselli JS, Bozinovski J, LeMaire SA. Open surgical repair of 2286 thoracoabdominal aortic aneurysm. Ann Thorac Surg. 2007;83:S862-4.

2. Cambria RP, Clouse WD, Davison JK, Dunn PF, Corey M, Dorer D. Thoracoabdominal aneurysm repair: results with 337 operations performed over a 15-year interval. Ann Surg. 2002;236:471-9.

3. Conrad MF, Crawford RS, Davison JK, Cambria RP. Thoracoabdominal aneurysm repair: a 20-year perspective. Ann Thorac Surg. 2007;83:S856-61.

4. Etz CD, Kari FA, Mueller CS, Silovitz D, Brenner RM, Lin HM, et al. The collateral network concept: a reassessment of the anatomy of spinal cord perfusion. $J$ Thorac Cardiovasc Surg. 2011;141:1020-8.

5. Bischoff MS, Di Luozzo G, Griepp EB, Griepp RB. Spinal cord preservation in thoracoabdominal aneurysm repair. Perspect Vasc Surg Endovasc Ther. 2011;23: 214-22.

6. Kulik A, Castner CF, Kouchoukos NT. Outcomes after thoracoabdominal aortic aneurysm repair with hypothermic circulatory arrest. J Thorac Cardiovasc Surg. 2011;141:953-60. 
7. Tabayashi K, Saiki Y, Kokubo H, Takahashi G, Akasaka J, Yoshida S, et al. Protection from postischemic spinal cord injury by perfusion cooling of the epidural space during most or all of a descending or thoracoabdominal aneurysm repair. Gen Thorac Cardiovasc Surg. 2010;58:228-34.

8. Safi HJ, Bartoli S, Hess KR, Shenaq SS, Viets JR, Butt GR, et al. Neurologic deficit in patients at high risk with thoracoabdominal aortic aneurysms: the role of cerebral spinal fluid drainage and distal perfusion. J Vasc Surg. 1994; 20:434-44.

9. Safi HJ, Miller CC, Huynh TT, Estrera AL, Porat EE, Winnerkvist AN, et al. Distal aortic perfusion and cerebrospinal fluid drainage for thoracoabdominal and descending thoracic aortic repair: ten years of organ protection. Ann Surg. 2003;238:372-80.

10. Safi HJ, Miller CC, Carr C, Iliopoulos DC, Dorsay DA, Baldwin JC. Importance of intercostal artery reattachment during thoracoabdominal aortic aneurysm repair. J Vasc Surg. 1998;27:58-66.

11. Acher CW, Wynn MM, Mell MW, Tefera G, Hoch JR. A quantitative assessment of the impact of intercostal artery reimplantation on paralysis risk in thoracoabdominal aortic aneurysm repair. Ann Surg. 2008;248:529-40.

12. Tanaka H, Ogino H, Minatoya K, Matsui Y, Okabayashi H, Saiki Y, et al. The impact of preoperative identification of the Adamkiewicz artery on descending and thoracoabdominal aortic repair. J Thorac Cardiovasc Surg. 2016;151:122-8.

13. Etz CD, Debus ES, Mohr FW, Kollbel T. First-in-man endovascular preconditioning of the paraspinal collateral network by segmental artery coil embolization to prevent ischemic spinal cord injury. J Thorac Cardiovasc Surg. 2015;149: 1074-9.

14. Panthee N, Ono M, Morota T, Tanaka T, Itoda Y, Ikemura M, et al. Paraplegia prevention by oral pretreatment with memantine in a rabbit model. J Thorac Cardiovasc Surg. 2014;148:1732-8.

15. Takahashi S, Isaka M, Hamaishi M, Imai K, Orihashi K, Sueda T. Trehalose protects against spinal cord ischemia in rabbits. J Vasc Surg. 2014;60: 490-6.

16. Lips J, de Haan P, Bouma GJ, Holman R, van Dongen E, Kalkman CJ. Continuous monitoring of cerebrospinal fluid oxygen tension in relation to motor evoked potentials during spinal cord ischemia in pigs. Anesthesiology. 2005; 102:340-5.

17. Sakurai M, Aoki M, Abe K, Sadahiro M, Tabayashi K. Selective motor neuron death and heat shock protein induction after spinal cord ischemia in rabbits. $J$ Thorac Cardiovasc Surg. 1997;113:159-64.

18. Yamauchi T, Sakurai M, Abe K, Takano H, Sawa Y. Neuroprotective effects of activated protein $\mathrm{C}$ through induction of insulin-like growth factor-1(IGF1), IGF-1 receptor, and its downstream signal phosphorylated serinethreonine kinase after spinal cord ischemia in rabbits. Stroke. 2006;37: 1081-6.

19. Tarlov IM. Acute spinal cord compression paralysis. J Neurosurg. 1972;36: 10-20.

20. Hellberg A, Ulus AT, Christiansson L, Westman J, Leppänen O, Bergqvist D, et al. Monitoring of intrathecal oxygen tension during experimental aortic occlusion predicts ultrastructural changes in the spinal cord. J Thorac Cardiovasc Surg. 2001;121:316-23.

21. Zhukhovitskii DI. Molecular dynamics study of nanobubbles in the equilibrium Lennard-Jones fluid. J Chem Phys. 2013;139:164513.

22. Matsuki N, Ichiba S, Ishikawa T, Nagano O, Takeda M, Ujike Y, et al. Blood oxygenation using microbubble suspensions. Eur Biophys J. 2012;41:571-8.

23. Fujita S, Sakurai M, Baba H, Abe K, Tominaga R. Autophagy-mediated stress response in motor neurons after hypothermic spinal cord ischemia in rabbits. $J$ Vasc Surg. 2015;62:1312-9.

24. Nazil Y, Colak N, Alpay MF, Uysal S, Uzunlar AK, Cakir O. Neuroprotective effect of atorvastatin in spinal cord ischemia-reperfusion injury. Clinics (Sao Paulo). 2015;70:52-60.

25. Takahashi G, Sakurai M, Abe K, Itoyama Y, Tabayashi K. MCI-186 reduces oxidative cellular damage and increases DNA repair function in the rabbit spinal cord after transient ischemia. Ann Thorac Surg. 2004;78:602-7.

26. Svensson LG, Stewart RW, Cosgrove DM III, Lytle BW, Antunes MD, Beven EG, et al. Intrathecal papaverine for the prevention of paraplegia after operation on the thoracic or thoracoabdominal aorta. J Thorac Cardiovasc Surg. 1988;96:823-9.

Key Words: thoracoabdominal aortic aneurysm repair, spinal cord ischemic injury, cerebrospinal fluid, nanobubbles

\section{Discussion}

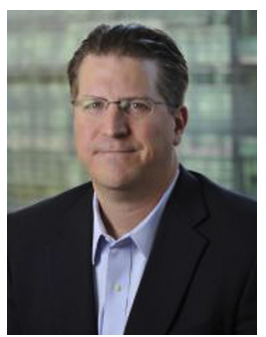

Dr T. B. Reece (Denver, Colo). The observation that CSF deoxygenation leading to treating with oxygenated fluid around the cord is interesting with the nanobubbles. Your outcomes are impressive, but I have a couple of questions.

First, the hypothesis is based on diffusion of oxygen into the cord from the CSF. The results suggest that there is uniform diffusion through the cord from the fluid. As I read, I assume that the protection would be improved on the periphery of the cord rather than in the central where the CSF doesn't have as free flow. Do you think this is truly uniform protection through the cord with oxygen delivery and will this play out for extended ischemic times or is this just a function of the 15-minute ischemic time?

Dr Kanda. Considering the nature of the gas and fluid, we can reasonably assume that the oxygen diffused through the entire cord. However, we could not prove it, because we did not obtain a real-time monitoring device for tissue oxygen content. In addition, it might be difficult to demonstrate significant diffusion of the oxygen at the higher level of the spinal cord where the tissue was not exposed to ischemia.

Dr Reece. But you would able to tell if the neurons are dead in the central part of the cord versus the outer. So I think there are proxies that you could look at to decide if there is a diffusion issue. Administration of CSF may increase the intrathecal pressure, which is the opposite of our current gold standard for treating these patients. How do you see this being incorporated in practice and would it require 2 drains as in CSF cooling, which has been presented before?

Dr Kanda. We share your concern on an increase in the intrathecal pressure. We measured the pressure at the end of arterial CSF infusion and found that intrathecal pressure was kept below $20 \mathrm{~mm} \mathrm{Hg}$. This level of intrathecal pressure is known to be tolerated clinically. Nonetheless, we have to pay attention not to induce excessive increase in intrathecal pressure. We agree with your suggestion to use 2 separate drains, and a double-lumen catheter with a proximal and distal fenestration will be another option to avoid unwanted intrathecal high pressure.

Dr Reece. Which could increase the leak. That would have to be worked out, and I am worried just about the pure space volume issue that you are giving with the 10 $\mathrm{mL}$ per hour.

Finally, it appears to work well within an occlusion reperfusion model that you have used in the rabbits, but how will your test in a model that sacrifices the intercostals or there is not reperfusion that the collaterals are going to have to recover over time? Specifically, would you propose ongoing 
CSF replacement for some time after the procedure or is this something that's only going to be done during the ischemic episode?

Dr Kanda. This is another important question and a clinically relevant point. We expect that CSF oxygenation can serve as a rescue oxygen provider until collateral blood supply is resumed after an occlusion of critical segmental artery. However, it is extremely difficult to prove it practically, because large animals such as a swine have an incredibly diverse spinal cord perfusion system.
Namely, occlusion of the anatomic critical segmental artery does not necessarily induce spinal cord ischemia. By the time we occlude multiple feeding arteries to see spinal cord ischemia or infarction, we end up with interruption of important collateral (inaudible) vessels, where CSF oxygenation can no longer exert a protective effect. It would be beneficial to continue CSF oxygenation until hemodynamics become stable postoperatively if you are sure that critical segmental arteries are occluded during the surgery.

Readers who found these articles interesting may also like to read the following papers found in recent and future issues of our sister publications, Seminars in Thoracic and Cardiovascular Surgery and Operative Techniques in Thoracic and Cardiovascular Surgery!

\section{Evolving Technology and Basic Science}

Original Submission: Creation and Global Deployment of a Mobile, Application-Based Cognitive Simulator for Cardiac Surgical Procedures. Zachary E. Brewer. Semin Thoracic Surg 2016; 28:1-9.

Editorial Commentary: “And” is Better Than “Or.” Joshua L. Hermsen. Semin Thoracic Surg 2016; 28:10-11. 